\title{
ANÁLISE DA SECAGEM DE LIMÃO TAHITI (CITRUS LATIFOLIA - TANAKA) EM FATIAS E DE SUAS FRAÇÕES: EPICARPO, MESOCARPO E ENDOCARPO
}

\author{
A. $\operatorname{SILVA}^{1^{*}}$, F. B. FREIRE $^{1}$, M. C. FERREIRA ${ }^{1 *}$ \\ ${ }^{1}$ Universidade Federal de São Carlos, Programa de Pós-Graduação em Engenharia Química \\ *e-mail: adriannasilva.78@gmail.com e mariaf@ufscar.br
}

\begin{abstract}
RESUMO
O limão tahiti (Citrus Latifolia - Tanaka) possui três frações distintas, sendo elas o epicarpo (casca externa), o mesocarpo (camada branca) e o endocarpo (polpa). Tanto o limão inteiro como suas frações possuem diversas aplicações na culinária, nas indústrias alimentícias e farmacêuticas. A secagem desse produto para fins alimentícios tem como desafios preservar os nutrientes e o bom aspecto visual ao final do processo. O objetivo deste trabalho é analisar a secagem das fatias e de cada fração do limão tahiti, isoladamente, em diferentes temperaturas e avaliar as alterações de cor e encolhimento que ocorrem na secagem, além de ajustar equações empíricas às curvas de cinética de secagem. Foram utilizadas para os ensaios as temperaturas de $50^{\circ} \mathrm{C}, 60^{\circ} \mathrm{C}$ e $70^{\circ} \mathrm{C}$, utilizando-se uma estufa com convecção natural do ar. Verificou-se que o epicarpo e mesocarpo foram as frações que secaram mais rapidamente, já o endocarpo e as fatias apresentaram taxas de secagem muito inferiores. Sob as condições avaliadas observouse que cada fração apresentou cinética de secagem distinta, devido às diferentes composição, dimensões, forma e estrutura de cada material. As equações de Page e Overhults forneceram os melhores ajustes aos dados experimentais. A variação total da cor foi maior para o endocarpo e para a fatia. $\mathrm{O}$ encolhimento foi maior nos instantes iniciais de secagem e a redução da área superficial das amostras foi de cerca de $33 \%$, em média.
\end{abstract}

\section{INTRODUÇÃO}

As frutas cítricas produzidas no país, em especial o limão tahiti (Citrus latifolia Tanaka), além de serem consumidas in natura servem como matéria prima para indústrias alimentícias, famacêuticas e químicas, essas indústrias utilizam-se dos componentes de suas partes (epicarpo, mesocarpo e endocarpo), para a fabricação de diversos produtos (VIANA, 2010).

O epicarpo, camada externa da casca, é composto por celulose, hemicelulose, lignina pectina, carotenóides e é rico em óleos essenciais (GOMES, 2011). Estes óleos essenciais possuem características flavorizantes, e são utilizado para aromatizar medicamentos, doces, bebidas diversas, sorvetes, produtos de limpeza e de perfumaria (TITA, 2011).

O mesocarpo, camada branca da casca, também tem sua estrutura constituída por celulose, hemicelulose, lignina, além da fibra solúvel pectina (GONÇALVES et al, 2001). Como é uma fonte rica em fibras solúveis, é utilizado como ração animal, suplementação alimentar humana, e como matéria prima para fabricação de doces em calda ou cristalizados e a pectina é ainda utilizada como aditivo espessante em geleias (MENDONÇA, 2006).

E por fim o endocarpo, ou polpa, possui vesículas de suco compostas por hemicelulose 
e celulose e o suco rico em vitamina $\mathrm{C}$, glicídeos solúveis, sais minerais e compostos fenólicos, todos com propriedades terapêuticas comprovadas à saúde humana (BEHLING et al, 2008).

$\mathrm{Na}$ Europa, Ásia e Ámérica do Norte são comercializados os limões secos inteiros ou em fatias, na forma de pó e das cascas granuladas. Este fruto processado possui aplicação direta na culinária, como condimento de assados, ensopados e saladas, no preparo de chás e de bebidas diversas. A secagem desta fruta é conveniente, uma vez que garante à mesma um maior tempo de prateleira, além de reduzir a dependência da sazonalidade, o que altera a disponibilidade do fruto no mercado, acarretando variações no preço final.

Produtos heterogêneos como o limão, podem envolver diferentes mecanismos de remoção de umidade, uma vez que cada fração possui características intrínsecas que determinam o modo como a água está ligada à sua estrutura. Em geral, os materiais biológicos secos são classificados de acordo com a sua estrutura e o tipo de ligação de água. Entretanto, uma grande variedade desses produtos, do ponto de vista da sua natureza e estrutura, não permitem a especificação exata da forma de ligação da umidade no material. Geralmente assume-se que estes materiais pertencem às substâncias coloidais-capilares-porosas, nas quais são possíveis todas as formas de ligação de umidade no material. Dessa forma um produto biológico possui água ligada com diferentes funções e efeitos sobre a preservação da qualidade e deterioração do produto (ADAMIEC et al, 2006).

De acordo com Perré e Keey (2006) a parede celular de materiais biológicos tem uma estrutura complexa, composta por uma rede de microfibras de celulose interligada por cadeias de hemicelulose incrustadas por pectinas e proteínas. A celulose é um polímero linear com um alto grau de polimerização. Segundo Adamiec et al (2006), nas macromoléculas desses biopolímeros a água está presente principalmente como água ligada.

Para produtos biológicos geralmente a secagem ocorre predominantemente à taxa decrescente. Nesta condição a resistência interna ao transporte de umidade predomina e os mecanismos de transporte de umidade são vários, entre os quais: a difusão líquida, o escoamento capilar e a difusão de vapor (FORNELL et al, 1980; PARK et al, 2004; COSTA, 2013).

A análise das curvas de cinética de secagem fornece informações a respeito do comportamento do produto durante a remoção de umidade, e a descrição matemática do processo auxilia no estudo do processo e também em projetos de secadores. Os fenômenos de transporte de calor e de massa ocorrem simultaneamente na secagem convectiva de produtos alimentícios e descrevê-los matematicamente usando modelos fenomenológicos específicos é uma tarefa difícil, pela grande quantidade de parâmetros necessários e de difícil determinação. Para facilitar a análise, equações empíricas e semi-empíricas, tais como as propostas por Lewis, Page, Overhults e Henderson e Pabis, são frequentemente utilizadas na literatura para descrever a cinética de secagem em detrimento da modelagem puramente teórica.

Foram encontrados na literatura poucos trabalhos relacionados à secagem de frutas cítricas. Khafajeh et al (2013) avaliaram a secagem convectiva de fatias de laranja e verificaram a influência que a espessura exercia na cinética de secagem. Os autores observaram a formação de uma crosta rígida na superfície formada pelos açúcares. Mas ainda assim a secagem nas temperaturas mais altas levou a tempos menores de secagem se comparada às temperaturas mais baixas.

Chen et al (2005) secaram fatias de limão siciliano e compararam a cinética de 
secagem e a cor do produto final utilizando dois secadores diferentes. As fatias que apresentaram melhor aspecto visual foram aquelas submetidas à secagem no secador solar fechado, operando com aumento gradual de temperatura, em relação ao secador convectivo com temperatura fixa.

Os produtos do gênero alimentícios sofrem alterações estruturais provocadas pela perda de umidade por meio da secagem convectiva, tais como encolhimento e alterações de cor. Tais modificações impactam diretamente na percepção de qualidade do produto final, características essas que são primeiramente observadas pelo consumidor ao adquirir qualquer produto alimentício processado (CHEN et al, 2005; CÓRDOVA, 2006).

Dentro do contexto apresentado e devido à heterogeneidade na composição das fatias, é conveniente uma análise da cinética de secagem de cada uma das suas frações individuais. Essa abordagem visa reunir informações a cerca do comportamento de cada parte durante a secagem, de forma que auxilie na compreensão dos fenômenos envolvidos na secagem da fatia.

Assim sendo, o presente trabalho tem como objetivo analisar a secagem das fatias e de cada fração do limão tahiti, epicarpo, mesocarpo e endocarpo, isoladamente, em diferentes temperaturas e avaliar o efeito da temperatura no processo. Além disso, avaliar as alterações de cor que ocorrem ao final do processo de secagem das fatias e suas frações, nas diferentes temperaturas, e o encolhimento das fatias. Serão efetuados ajustes de equações empíricas e semi-empíricas aos dados experimentais de cinética de secagem.

\section{MATERIAIS E MÉTODOS}

A matéria prima utilizada foi $\mathrm{o}$ limãotahiti, adquirido em um estabelecimento da cidade de São Carlos-SP, dando-se preferência aos frutos com dimensões e características visuais de maturação semelhantes. Antes dos ensaios, os frutos foram higienizados com água clorada. O epicarpo e o mesocarpo foram separados manualmente com a ajuda de uma faca de cozinha. $\mathrm{O}$ endocarpo teve a casca removida, mantendo-se apenas a membrana que reveste os gomos. Os gomos foram então separados e fatiados também com uma faca de cozinha, formando pedaços triangulares com espessura média de $2,5 \mathrm{~mm}$, aferida com um paquímetro digital (precisão de $0,01 \mathrm{~mm}$ ). Para o corte das fatias foi utilizado um processador de alimentos doméstico, que produz fatias com espessura média de $2,4 \mathrm{~mm}$. Imagens das fatias inteiras, do epicarpo, mesocarpo e do endocarpo são mostradas na Figura 1.

Figura 1 - Matéria prima utilizada nos ensaios (a) epicarpo, (b) mesocarpo, (c) endocarpo e (d) fatias.
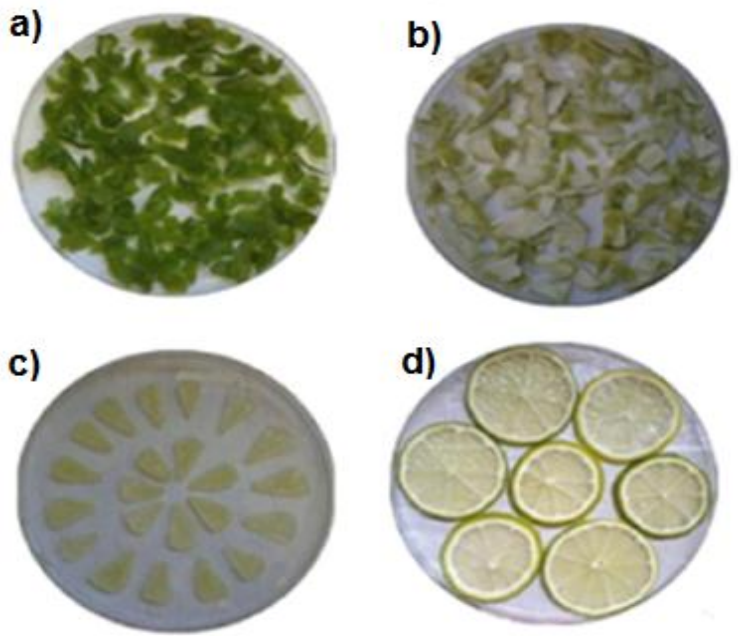

Fonte: Autor (2015).

A determinação da umidade inicial das amostras foi realizada utilizando amostras com massas iniciais conhecidas, que foram levadas à estufa a vácuo marca Tecnal, modelo TE-395, operando na temperatura de $70^{\circ} \mathrm{C}$ por 24 horas, de acordo com metodologia descrita pela AOAC (1995) adaptada por PARK et al, (2001). A pesagem foi feita em balança semi-analítica marca GEHAKA modelo 440 (precisão 0,001 g), e a 
umidade foi calculada através da variação de massa inicial e final, considerando que a diferenças corresponde à água evaporada.

Os ensaios de secagem convectiva foram conduzidos em estufa de convecção natural, marca Tecnal, modelo TE-394/1, de escala laboratorial. Cada uma das amostras citadas foi submetida à secagem nas temperaturas de $50^{\circ} \mathrm{C}, 60^{\circ} \mathrm{C}$ e $70^{\circ} \mathrm{C}$ com duas ou três repetições, até que atingisse a massa constante ao final de cada processo. Para a verificação da variação de massa de cada material durante os ensaios, foi utilizada também uma balança semi-analítica marca GEHAKA modelo 440 (precisão 0,001 g).

Para representar as cinéticas de secagem efetuou-se o ajuste dos dados experimentais às equações empíricas de Lewis, Page, Overhults e Henderson e Pabis. Os parâmetros das equações foram determinados pelo método da minimização da soma dos quadrados dos resíduos, com a ajuda do suplemento Solver, presente no software Microsoft Excel 2010. Foram considerados como melhores ajustes aquelas equações que forneceram o maior valor de $\mathrm{R}^{2}$ e o menor valor da soma dos quadrados dos resíduos.

Os ensaios colorimétricos para a determinação da cor das fatias e das frações da matéria prima foram executados empregando-se um espectrofotômetro marca Konica Minolta, modelo CM-5, com sistema de leitura CIELab, configurado com luminosidade D65 e ângulo de observação de $10^{\circ}$. As amostras passaram pela análise colorimétrica antes da secagem para a obtenção de um padrão e depois de cada processo de secagem. $\mathrm{O}$ equipamento forneceu os parâmetros colorimétricos $\left(\mathrm{L}^{*}, \mathrm{a}^{*}\right.$ e $\left.b^{*}\right)$. Com os valores obtidos desses parâmetros, foi calculada a diferença média de cor entre o material fresco e processado por meio da Equação 1.

$$
\Delta E^{*}=\sqrt{\left[\left(L_{\text {fin }}-L_{\text {ini }}\right)^{2}+\left(a_{\text {fin }}-a_{\text {ini }}\right)^{2}+\left(b_{\text {fin }}-b_{\text {ini }}\right)^{2}\right]}
$$

Para a análise do encolhimento das fatias, as amostras foram fotografadas, antes e depois do processo, com uma câmera digital marca Samsung, modelo ES60, e as imagens digitais foram analisadas por meio do software Image-Pro Plus $6^{\circledR}$. O software foi calibrado utilizando-se para isso o diâmetro interno da placa de petri utilizada nos ensaios, por ser de uma dimensão conhecida (146 mm) e comum em todos os ensaios. A análise de imagem foi efetuada pelo programa, que forneceu as áreas superficiais das fatias, em milímetros.

\section{RESULTADOS E DISCUSSÃO}

As umidades iniciais médias em base úmida do epicarpo e do mesocarpo foram de $73 \%$, de $89 \%$ para o endocarpo e para as fatias foi de $85 \%$. Para as fatias, as umidades iniciais estão de acordo com os valores reportados por Khafajeh et al (2013), que encontraram o valor de $85,4 \%$ para fatias de laranja.

Nos ensaios de secagem e suas repetições para o epicarpo, mesocarpo, endocarpo e fatias, seus adimensionais de umidade apresentaram valores médios dos desvios padrão de no máximo $3 \%$ e $\mathrm{R}^{2}$ de 0,99 , com isso é possível inferir que houve boa reprodutibilidade dos dados nos ensaios. Assim, serão apresentados e discutidos os resultados baseados em valores médios dos adimensionais de umidade para cada material. Os resultados das cinéticas de secagem obtidas para as condições estudadas são apresentados na Figura 2.

$\mathrm{Na}$ Figura 2 verifica-se que o epicarpo e o mesocarpo apresentaram cinéticas de secagem similares em todos os casos, sendo as frações em que a umidade foi removida mais rapidamente em comparação com o endocarpo e a fatia. Este comportamento pode ser atribuído ao fato do epicarpo e de mesocarpo possuírem vários componentes em comum em sua composição (celulose, hemi- 
celulose, lignina). A geometria usada na secagem também é similar, na forma de lascas finas, com elevada área específica que favorece e remoção de umidade.

Comparando-se a secagem destas frações e das fatias com a secagem do endocarpo, verifica-se que a cinética de secagem desta fração foi intermediária entre as demais, comportamento que se repetiu em todas as temperaturas. Neste caso, o material possui formato e espessura definidas, e sua composição é bem diferente do epicarpo e mesocarpo. O endocarpo é constituído principalmente pelas vesículas de suco e possui o maior teor de umidade inicial entre as frações. A membrana que envolve as vesículas de suco, contudo, forma uma barreira para a saída de umidade. Outro ponto a ser ressaltado é o fato de ter sido observada em todas as temperaturas a formação de caramelo na superfície provocado pelos açúcares presentes no suco do limão, tornando a superfície do material enrijecida. Khafajeh et al (2013) também relataram a formação de caramelo e crosta enrijecida na superfície das fatias de laranja, submetidas à secagem convectiva, e atribuíram o longo tempo de secagem à camada endurecida, que dificulta a remoção de umidade na superfície do sólido.

Ao se analisar a secagem das fatias, observa-se que ela apresentou cinéticas de secagem bem mais lentas do que a das frações. O tempo requerido para atingirem a umidade de equilíbrio dinâmica foi o maior que o de suas frações, em todas condições de temperatura. Porém, com o aumento da temperatura, a diferença diminuiu e a cinética de secagem da fatia tende a se aproximar da cinética do endocarpo.

Em uma primeira análise, a secagem bem mais lenta das fatias não era um comportamento esperado, visto que a fatia é uma composição das três frações que forneceram cinéticas mais rápidas, portanto esperava-se que sua secagem fosse intermediária em relação às suas partes. A secagem da fatia é resultado da contribuição de cada uma das frações, portanto é influenciada pela composição e características de todas elas.

Contudo, a fatia do limão forma uma estrutura única composta pelas três frações que se encontram conectadas entre si. Essa composição resulta em uma estrutura complexa, na qual diferentes mecanismos de transporte de umidade estão presentes, o que dificulta a descrição do processo com base em modelos fenomenológicos. A cinética de secagem das fatias mostra que a resistência à perda de umidade do conjunto não corresponde à média das resistências observadas nas frações individuais.

Ainda observando a Figura 2, nota-se que houve influência significativa da temperatura nos tempos de secagem principalmente para o endocarpo e para as fatias. A secagem do epicarpo e do mesocarpo não sofreram influência expressiva da temperatura, o que pode ser observado comparando-se os tempos de secagem.

Na Figura 3 são apresentadas as taxas de secagem em todas as temperaturas avaliadas, onde verifica-se que o período de secagem à taxas decrescentes foi predominante para todos os materiais estudados. O período de secagem à taxa constante não foi observado em nenhuma das condições, assim como relatam outros autores que estudaram a secagem de produtos alimentícios (PARK et al, 2001). A temperatura de $70^{\circ} \mathrm{C}$ forneceu as maiores taxas de secagem, sendo que para o epicarpo, mesocarpo, endocarpo e a fatia os valores máximos foram de $0,035,0,03,0,07 \mathrm{e}$ de 0,025 (gágua $/ \mathrm{g}_{\mathrm{ss}} \cdot \mathrm{min}$ ), respectivamente, para altas umidades. Em todas as temperaturas avaliadas foi observado o período inicial de aquecimento, caracterizado pela transferência de calor do ar para o material, até que o mesmo atinja o equilíbrio térmico com o ar de secagem. 
Figura 2 - Umidades adimensionais em função do tempo para o epicarpo, mesocarpo, endocarpo e fatia do limão tahiti, nas temperaturas de (a) $50^{\circ} \mathrm{C}$, (b) $60^{\circ} \mathrm{C}$ e (c) $70^{\circ} \mathrm{C}$.

(a)

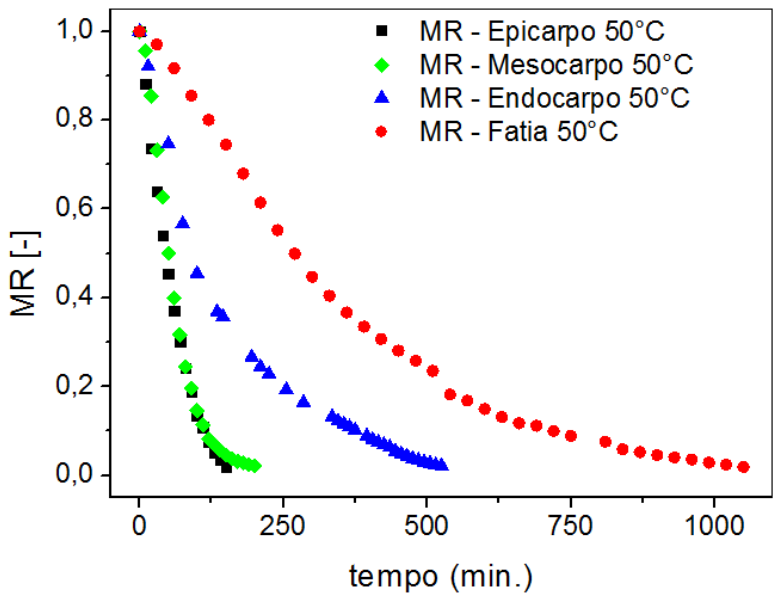

(b)

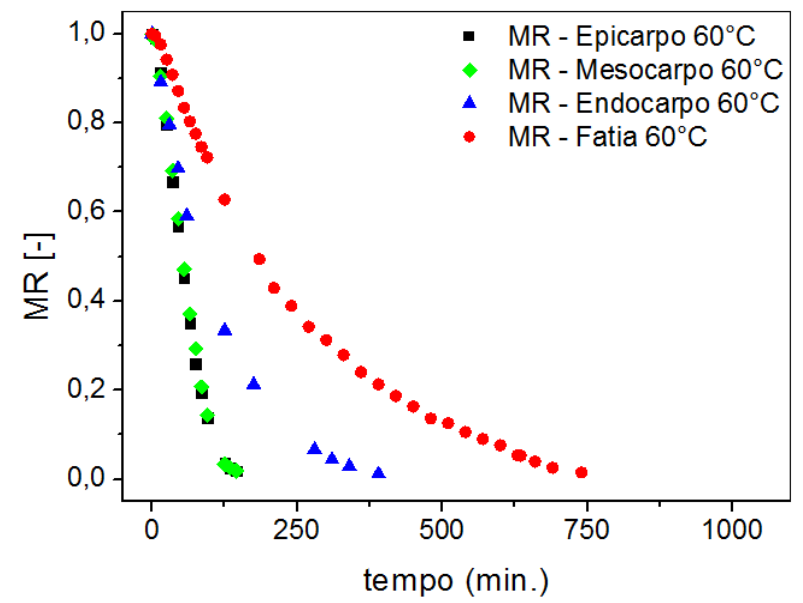

(c)

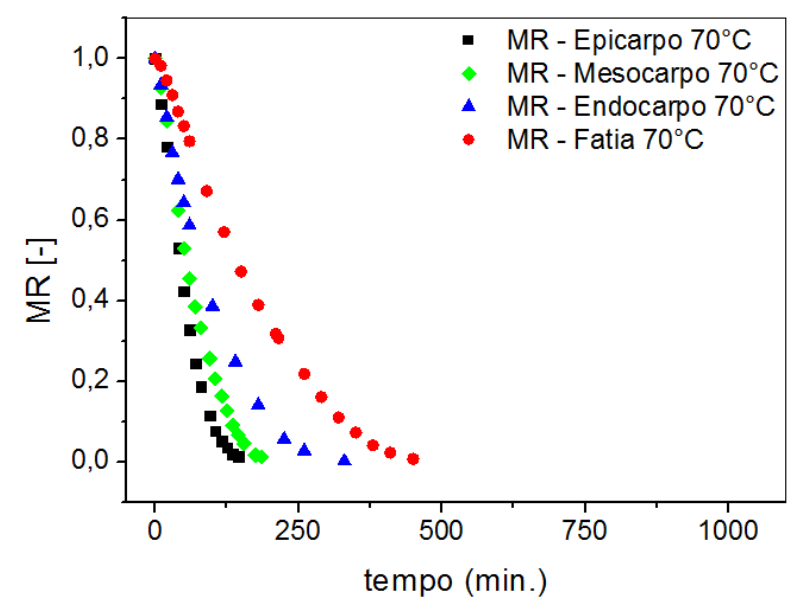

Fonte: Autor (2015).
Figura 3 - Taxa de secagem em função de MR, para o epicarpo, mesocarpo, endocarpo e fatia do limão tahiti, nas temperaturas de (a) $50^{\circ} \mathrm{C}$, (b) $60^{\circ} \mathrm{C}$ e (c) $70^{\circ} \mathrm{C}$.

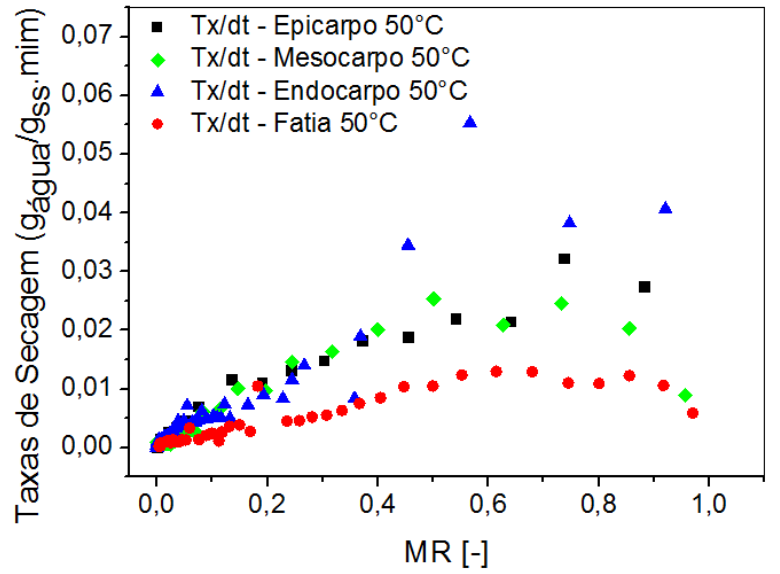

(b)

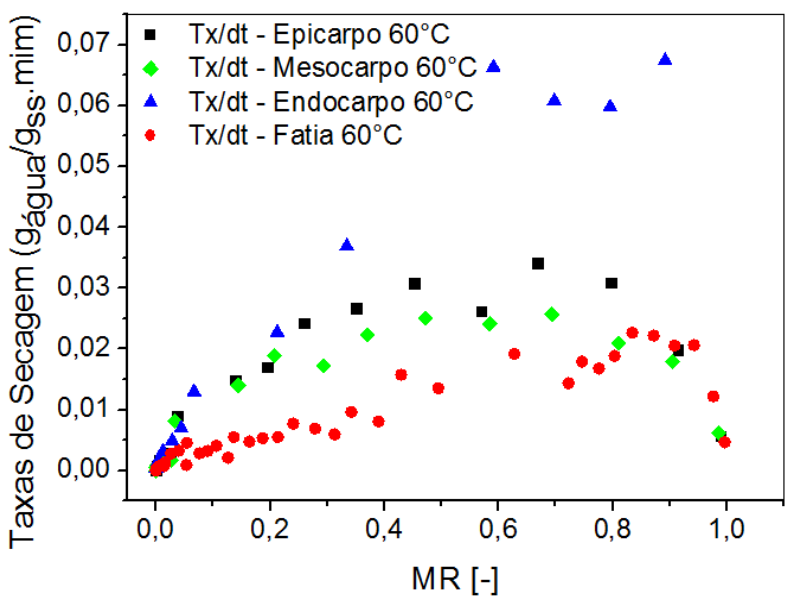

(c)

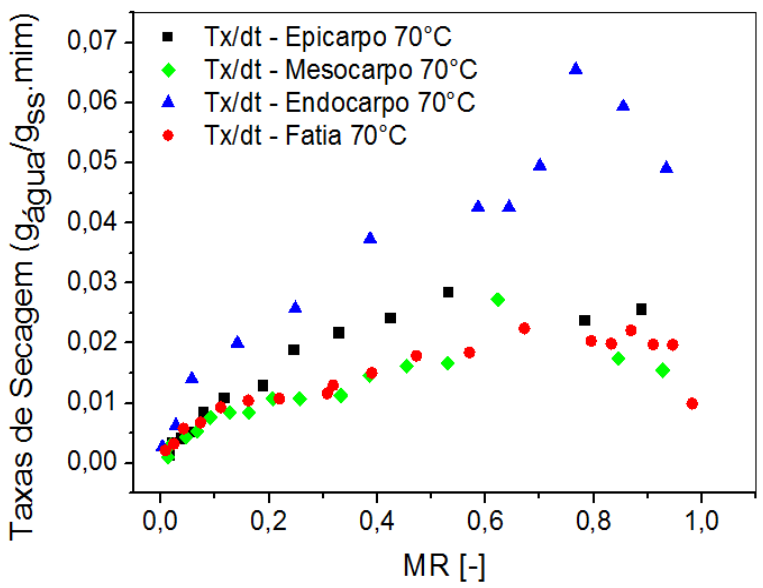

Fonte: Autor (2015). 
Com base no comportamento das taxas, é possível inferir que os fenômenos de transferência envolvidos estão relacionados aos mecanismos internos de migração de umidade, de modo que a resistência interna ao material é o fator limitante dos processos de secagem das frações e das fatias.

\subsection{Ajustes das equações de cinética de secagem}

De maneira geral, os ajustes das equações de Page e Overhults aos dados experimentais mostraram-se bons para todos os materiais nas condições estudadas, visto que a maioria resultou em valores de $R^{2}$ próximos a unidade e baixos valores de $S Q R$, em torno de 0,004. Para ilustrar a boa qualidade dos ajustes das equações de Page e de Overhults aos dados experimentais, é apresentada a Figura 4, para as temperaturas de $50^{\circ} \mathrm{C}$ e $70^{\circ} \mathrm{C}$ para as fatias.

Figura 4 - MR em função do tempo com os ajustes das equações de Page e de Overhults nas temperaturas de $50^{\circ} \mathrm{C}$ e $70^{\circ} \mathrm{C}$ para as fatias.

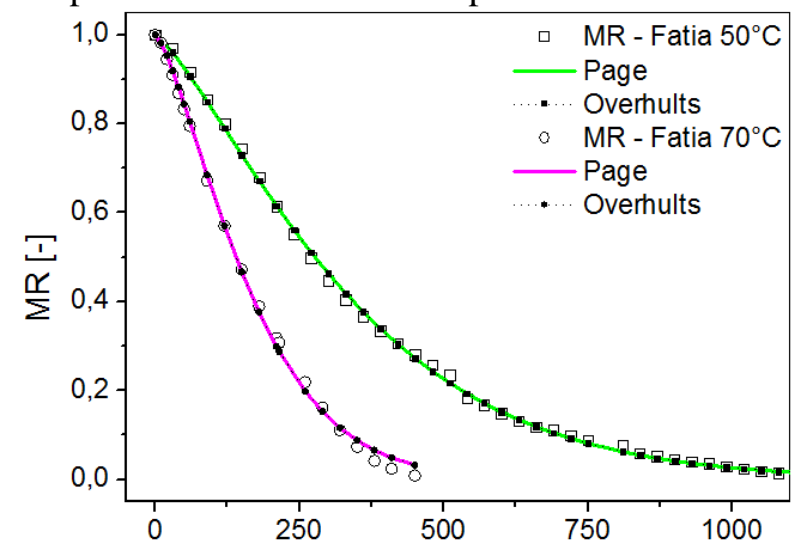

Fonte: Autor (2015).

\subsection{Atributos de qualidade}

\subsubsection{Cor}

Nos ensaios colorimétricos foram avaliados os efeitos das diferentes temperaturas utilizadas. Na Figura 5, são mostradas fotos das amostras das fatias in natura e secas em $50^{\circ} \mathrm{C}$ e $70^{\circ} \mathrm{C}$. É possível notar o escurecimento das fatias após a secagem.

Figura 5 - Fatias (a) in natura e secas em (b) $50^{\circ} \mathrm{C}$ e em (c) $70^{\circ} \mathrm{C}$.
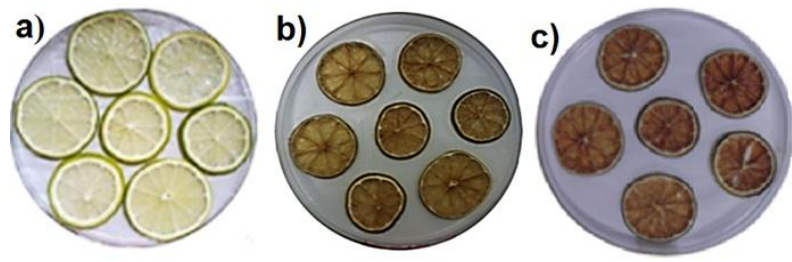

Fonte: Autor (2005).

As análises dos parâmetros colorimétricos efetuadas para cada fração forneceu a variação da cor total $\left(\Delta \mathrm{E}^{*}\right)$. Os resultados obtidos em cada temperatura e para cada material são apresentados na Figura 6.

Figura 6 - Variação total da cor das frações e das fatias do limão, nas temperaturas avaliadas.

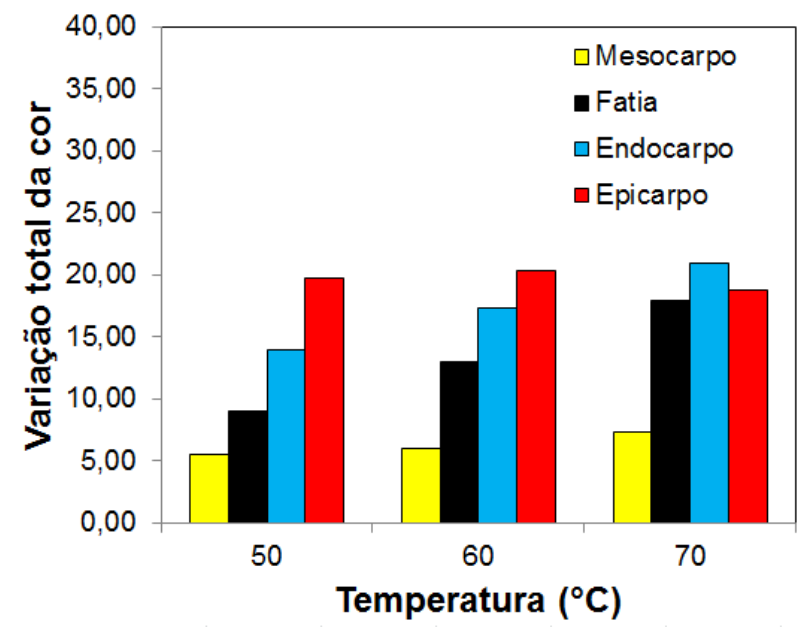

Fonte: Autor (2015).

Nota-se que as variações de cor total foram expressivas para o endocarpo, sendo observado um acréscimo de $63 \%$ em $\Delta \mathrm{E}^{*}$ entre a menor e a maior temperatura, enquanto para a fatia esta diferença foi de 73\% para o mesmo intervalo de temperaturas. A mudança de cor para estes materiais pode estar relacionada com possíveis reações de oxidação enzimática sofridas pela polpa do limão e podem ser indício de perda de 
nutrientes. Seria necessária uma investigação específica para avaliar de forma completa o efeito da temperatura nas propriedades do fruto.

\subsubsection{Encolhimento}

Em todas as temperaturas avaliadas houve encolhimento das fatias durante a secagem, atingindo redução de aproximadamente $7 \mathrm{~cm}^{2}$ de área superficial. Este encolhimento representa uma perda de cerca de $33 \%$ em relação a área inicial. O encolhimento apresentado foi praticamente o mesmo em todos os ensaios, com desvios padrão de no máximo $2 \%$. Isso se justifica pelo fato do encolhimento estar associado à quantidade de água removida do material que foi similar para todas as condições. Entretanto, mesmo com alto percentual de encolhimento, as fatias mantiveram seu formato como pode ser observado na Figura 5. A Figura 7 mostra a razão entre as áreas final e inicial em função da umidade para a secagem a $60^{\circ} \mathrm{C}$. O comportamento mostrado nesta figura é ilustrativo do que foi observado também para outras temperaturas, que por concisão não serão apresentados aqui.

Figura 7 - Razão entre as áreas superficiais finais e iniciais em função da umidade para a secagem das fatias de limão na temperatura de $60^{\circ} \mathrm{C}$.

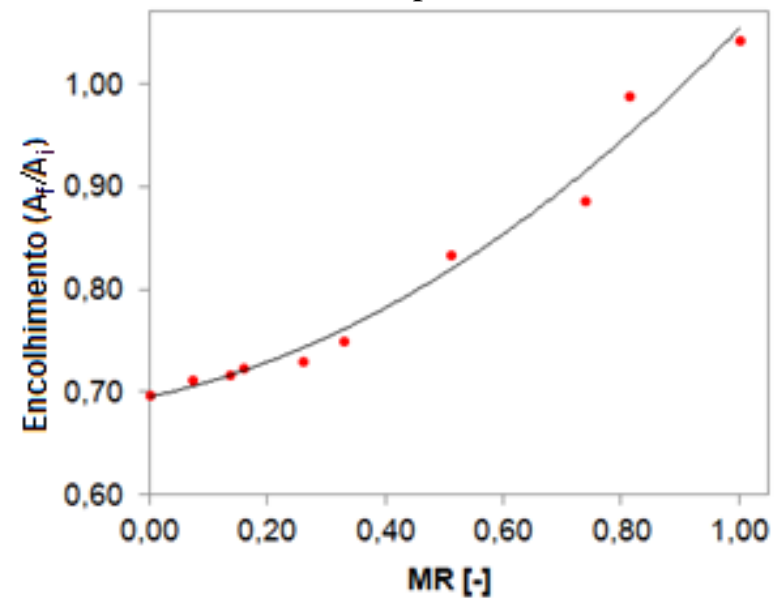

Fonte: Autor (2015).
Nota-se que o encolhimento foi mais intenso nos instantes iniciais da secagem com umidades iniciais elevadas, e a partir do adimensional de umidade de 0,33 o encolhimento foi suave até os instantes finais da secagem. Este mesmo comportamento foi foi reportado por Yan et al (2008), que observou que o encolhimento se estabilizou partir da umidade em torno de $30 \%$ (b.u.) na secagem convectiva de fatias de banana, manga e abacaxi.

\section{CONCLUSÕES}

Com os resultados obtidos é possível concluir que a secagem de cada fração ocorre com taxas diferentes a uma dada temperatura, sendo que as fatias apresentaram as cinéticas mais lentas. O período de secagem à taxa decrescente foi o único observado em todas as condições, demonstrando que a resistência interna ao transporte de umidade é a resistência controladora do processo. O efeito da temperatura foi significativo em toda a faixa de temperaturas avaliadas para a secagem do endocarpo e para a fatia.

As equações de Page e de Overhults, forneceram os melhores ajustes aos dados experimentais portanto são recomendados para estimar a cinética de secagem da fatia e das frações do limão.

A variação de cor total entre as amostras secas e as amostras in natura foram expressivas para as fatias e o endocarpo, e aumentaram com o aumento da temperatura. Para o epicarpo e o mesocarpo essa variação não foi significativa. Conclui-se que o endocarpo foi o principal responsável pelo escurecimento da fatia.

$\mathrm{O}$ encolhimento na área superficial foi, em média, de $33 \%$ em relação a fatia in natura, sendo observado encolhimento mais intenso nos instantes iniciais da secagem. 


\section{NOMENCLATURA}

$a^{*} \quad$ parâmetro colorimétrico (verdevermelho);

b* parâmetro colorimétrico (amarelo-

azul);

b.s. base seca;

b.u. base úmida;

g gramas;

L* parâmetro colorimétrico de

luminosidade;

MR adimensional de umidade;

SQR soma do quadrado dos resíduos;

$\Delta \mathrm{E}^{*}$ variação total da cor do material.

\section{REFERÊNCIAS}

ADAMIEC, J.; KAMINSKI, W.; MARKOWSKI, A. S.; STRUMILLO, C. Drying of Biotechnological Products. In: Handbook of Industrial Drying, 3 ed. Nov 2006, cap. 39, p. 906-908

AOAC (Association of Official Analytical Chemists). Official Methods of analysis of AOAC international. 16 ed. Washington, DC.1995.

BEHLING, E.; SENDÃO, M. C.; FRANCESCATO, H. D. C.; ANTUNES, L. M. G.; BIANCHI, M. D. L. P. Flavonóide quercetina: aspectos gerais e ações biológicas. Alimentos e Nutrição Araraquara, v. 15, n. 3, p. 285-292, 2008.

CHEN, H-H.; HERNANDES, C. E.; HUANG, T-C. A study of the drying effect on lemon slices using a closed-type solar dryer. Solar Energy, v.78, p. 97-103. 2005.

COSTA, A. B. S. Secagem convectiva de folhas de hortelã: análise baseada no ajuste de correlações empíricas, superfícies de resposta e redes neurais. 2013. $91 \mathrm{f}$. Dissertação (Mestrado em Engenharia Química) - Universidade Federal de São Carlos, São Carlos, 2013.
CÓRDOVA, K. R. V. Desidratação osmótica e secagem convectiva de maçã fuji comercial e industrial, 2006. 148 f. Dissertação (Mestrado) - Universidade Federal do Paraná, Curitiba.

FORNELL, A.; BIMBENET, J. J.; ALMIN, Y. Experimental study and modelization for air drying of vegetable products. Lebensmittel-Wisenschaft \& technologie, v. 14, n.1, p.96-100, 1980.

GOMES, M. S. Caracterização química e atividade antifúngica dos óleos essenciais de cinco espécies do gênero Citrus, 2011. 98 f. Dissertação (Mestrado em Agroquímica) Universidade Federal de Lavras, Lavras, 2011.

GONÇALVES，L. C.; FILIZOLA， R. G.; CONCEIÇÃO, M. L. D.; SILVA, C. C. D. M.; ANDRADE, Y. O. D. Reciclagem das cascas da laranja pêra na produção de suplemento alimentar de fibras solúveis (pectina). In: Saneamento ambiental: desafio para o século 21, ABES, 2001. p.1-5.

KHAFAJEH, H.; BANAKAR, A.; GHOBADIAN, B.; MOTEVALI, A. Drying of orange slices in CHP dryer. Advances in Environmental Builogy, v. 7, n. 9, p. 23262332, set. 2013

MENDONÇA, L. M. V. L. et al. Caracterização da composição química e do rendimento dos resíduos industriais do limão tahiti (Citrus latifolia - Tanaka). Ciência e Tecnologia de Alimentos, v. 26, n. 4, p. 870874, 2006.

PARK, K. J.; YADO, M. K. M; BROD, F. P. R. Estudo de secagem de pêra barlett (Pyrus $S P)$ em fatias. Ciência e Tecnologia de Alimentos, v. 21, n. 3, p. 288-292, set-dez. 2001. 
PARK, K. J.; TUBONI, C. T.; OLIVEIRA, R. A.; PARK, K. J. B. Estudo da secagem de caqui giombo com encolhimento e sem encolhimento. Revista Bras. De Prod. Agroindustriais, v. 6, n. 1, p. 71-86, 2004.

PERRÉ, P.; KEEY, R. B. In: Handbook of Industrial Drying, 3 ed. Nov 2006, cap. 36, p. 826-827

TITA, M. L. Identificação dos componentes do óleo essencial de laranja (Citrus sinensis L. Osbeck) e proposição de procedimentos industriais para a obtenção de produtos diferenciados. 2011. 92 f. Dissertação (Mestrado em Química) Universidade Federal de São Carlos, São Carlos, 2011

VIANA, D. S. Limão (Citrus latifolia, Tanaka), cv. tahiti, de cultivos convencional e orgânico biodinâmico: avaliação da capacidade antioxidante dos sucos in natura e clarificados por membranas de microfiltração, 2010. $100 \mathrm{f}$. Dissertação (Mestrado em Ciências Farmacêuticas) - Universidade Federal do Rio de Janeiro, Faculdade de Farmácia, Rio de Janeiro, 2010.

YAN, Z.; SOUZA-GALLAGHER, M. J.; OLIVEIRA, F. A. R. Shrinkage and porosity of banana, pineapple and mango slices during air-drying. Journal of Food Engineering. n. 84, p. 430-440, 2008.

\section{AGRADECIMENTOS}

Ao Programa de Pós-Graduação em Engenharia Química UFSCar pela oportunidade, ao Centro de Secagem de Pastas e Sementes (DEQ/UFSCar), que forneceu o aparato necessário para que este trabalho fosse realizado e ao $\mathrm{CNPq}$ pelo apoio financeiro. 